\title{
Synthesis, crystal structure and properties of $\mathrm{SmBaCo}_{2-x} \mathrm{Fe}_{x} \mathrm{O}_{5+\delta}$
}

\author{
N.E. Volkova ${ }^{\text {a }}$, L.Ya. Gavrilova ${ }^{\text {a }}$, V.A. Cherepanov ${ }^{\text {a,* }}$, T.V. Aksenova ${ }^{\text {a }}$, V.A. Kolotygin ${ }^{\mathrm{b}}$, \\ V.V. Kharton ${ }^{\text {b }}$ \\ ${ }^{a}$ Department of Chemistry, Ural Federal University, Yekaterinburg, Russia \\ b Department of Materials and Ceramic Engineering, CICECO, University of Aveiro, Portugal
}

\section{A R T I C L E I N F O}

\section{Article history:}

Received 6 April 2013

Received in revised form

24 May 2013

Accepted 3 June 2013

Available online 13 June 2013

\section{Keywords:}

Double perovskite

Iron substituted samarium barium cobaltite

Crystal structure

Oxygen content

Thermal expansion

Conductivity

\begin{abstract}
A B S T R A C T
The solid solution formation range in the $\mathrm{SmBaCo}_{2-x} \mathrm{Fe}_{x} \mathrm{O}_{5+\delta}(0 \leq x \leq 2)$ system examined at $1100{ }^{\circ} \mathrm{C}$ in air corresponds to $0 \leq x \leq 1.1$. The crystal structure of $\mathrm{SmBaCo}_{2-x} \mathrm{Fe}_{x} \mathrm{O}_{5+\delta}$ with $x \leq 0.5$ was described as orthorhombic (space group Pmmm), and with $0.6 \leq x \leq 1.1$-as tetragonal $(P 4 / \mathrm{mmm})$. The introduction of iron into the cobalt sublattice leads to a gradual increase of the unit cell parameters and volume, accompanied with increasing oxygen content determined by thermogravimetry. The dilatometric curves collected at $25-1100{ }^{\circ} \mathrm{C}$ in air exhibit moderate nonlinearities associated with the orthorhombic $\rightarrow$ tetragonal phase transition, as confirmed by the high-temperature X-ray diffraction analysis. Temperature dependencies of the electrical conductivity measured by 4-probe dc method in the temperature range $25-1000{ }^{\circ} \mathrm{C}$ in air display maxima at $300-350{ }^{\circ} \mathrm{C}$, whilst the conductivity decreases with iron additions. These trends were discussed in terms of the defect structure and nature of the main charge carriers in $\mathrm{SmBaCO}_{2-x} \mathrm{Fe}_{x} \mathrm{O}_{5+\delta}$. It was also shown that $\mathrm{SmBaCo}_{2-\chi} \mathrm{Fe}_{x} \mathrm{O}_{5+\delta}$ is chemically stable with respect to the $\mathrm{Ce}_{0.8} \mathrm{Sm}_{0.2} \mathrm{O}_{1.9}$ solid electrolyte up to $1100{ }^{\circ} \mathrm{C}$, but reacts with $\mathrm{Zr}_{0.85} \mathrm{Y}_{0.15} \mathrm{O}_{1.93}$ even at $900{ }^{\circ} \mathrm{C}$.
\end{abstract}

(c) 2013 Elsevier Inc. All rights reserved.

\section{Introduction}

An unique set of transport, thermomechanical and interfacial properties of perovskite-like $\mathrm{LnBaCO}_{2} \mathrm{O}_{5+\delta}(\mathrm{Ln}=\mathrm{Pr}-\mathrm{Ho}, \mathrm{Y})$ makes it possible to use these materials for fuel cell electrodes and oxygenpermeable membranes [1-4] and attracts significant attention during last years [5-9]. Due to the large difference between the ionic radii of $\mathrm{Ln}^{3+}$ and $\mathrm{Ba}^{2+}$, these cations are located in separate layers of the $\mathrm{LnBaCO}_{2} \mathrm{O}_{5+\delta}$ structure, leading to doubling of $c$-parameter in the resultant tetragonal unit cell $\left(a_{p} \times a_{p} \times 2 a_{p}\right)$. However, a wide range of oxygen stoichiometry variations and ordering of oxygen vacancies in the vicinity of oxygen index equal to 5.5 yield doubling of the perovskite unit cell along the $b$-axis or, in other words, cause the formation of orthorhombic structure with $a_{p} \times 2 a_{p} \times 2 a_{p}$. Important advantages of the cobaltates with the double perovskite structure as potential cathode materials for solid oxide fuel cells (SOFCs) include a high electronic conductivity in combination with fast oxygen diffusion and interfacial oxygen exchange, which are often superior with respect to the disordered perovskite analogs. These materials exhibit also, however, high chemical reactivity with solid oxide electrolytes [1,2]. A common approach to solve this problem is related to doping. One can expect,

\footnotetext{
* Corresponding author. Fax: +7 3432615978

E-mail addresses: Vladimir.Cherepanov@usu.ru, vl_cherepanov@mail.ru (V.A. Cherepanov).
}

in particular, that iron substitution in $\mathrm{LnBaCo}_{2-\mathrm{x}} \mathrm{Fe}_{x} \mathrm{O}_{5+\delta}(\mathrm{Ln}=\mathrm{Pr}-\mathrm{Ho})$ should increase chemical stability of rare-earth barium cobaltates [10-14]. However, information regarding the formation and properties of Fe-containing solid solution based on $\mathrm{SmBaCO}_{2} \mathrm{O}_{5+\delta}$ is still scarce. Continuing our preliminary report on this system [15], the present work was centered on the studies of crystal structure, oxygen nonstoichiometry, thermal expansion and electrical conductivity of $\mathrm{SmBaCO}_{2-\gamma} \mathrm{Fe}_{x} \mathrm{O}_{5+\delta}(0 \leq x \leq 2)$. Also, chemical stability with respect to $\mathrm{Ce}_{0.8} \mathrm{Sm}_{0.2} \mathrm{O}_{1.9}$ and $\mathrm{Zr}_{0.85} \mathrm{Y}_{0.15} \mathrm{O}_{1.93}$, two common solid electrolyte materials used for SOFCs, was evaluated.

\section{Experimental}

Polycrystalline samples of $\mathrm{SmBaCO}_{2-x} \mathrm{Fe}_{x} \mathrm{O}_{5+\delta}(0 \leq x \leq 2)$ were prepared by the glycine-nitrate synthesis route using high-purity $\mathrm{Sm}_{2} \mathrm{O}_{3}, \mathrm{BaCO}_{3}$, metallic $\mathrm{Co}$ and $\mathrm{FeC}_{2} \mathrm{O}_{4} \cdot 2 \mathrm{H}_{2} \mathrm{O}, \mathrm{HNO}_{3}$ and glycine as starting materials. The required amounts of the starting materials annealed in air to remove absorbates were dissolved in the $4.5 \mathrm{M}$ nitric acid while heating; then glycine was added in the amount equivalent to a complete reduction of nitrate groups. The obtained solutions were dried to viscous gels that further transformed to brown powders, and then fired at $500-900{ }^{\circ} \mathrm{C}$. Final annealing was performed at $1100^{\circ} \mathrm{C}$ in air during $120 \mathrm{~h}$ with intermediate grindings, followed by slow cooling down to room temperature at a rate of about $100^{\circ} / \mathrm{h}$. 
The samples of $\mathrm{Ce}_{0.8} \mathrm{Sm}_{0.2} \mathrm{O}_{1.9}$ and $\mathrm{Zr}_{0.85} \mathrm{Y}_{0.15} \mathrm{O}_{1.93}$ solid electrolytes were obtained by the glycine-nitrate technique and coprecipitation method respectively. The former was prepared using the procedure similar to that described above, using $\mathrm{Ce}$ $\left(\mathrm{CO}_{3}\right)_{2} \cdot 2 \mathrm{H}_{2} \mathrm{O}$ and pre-annealed $\mathrm{Sm}_{2} \mathrm{O}_{3}$ as the starting materials. In order to prepare $\mathrm{Zr}_{0.85} \mathrm{Y}_{0.15} \mathrm{O}_{2}$ the stoichiometric amounts of $\mathrm{Zr}$ $(\mathrm{OH})_{2} \mathrm{CO}_{3} \cdot \mathrm{H}_{2} \mathrm{O}$ и $\mathrm{Y}_{2} \mathrm{O}_{3}$ were dissolved in nitric acid while heating; then an aqueous solution of $\mathrm{NH}_{4} \mathrm{OH}$ was added as precipitating agent. The resulting amorphous precipitate was thoroughly washed by water, dried at $100{ }^{\circ} \mathrm{C}$ during $6 \mathrm{~h}$ and finally annealed at $700{ }^{\circ} \mathrm{C}$ during $10 \mathrm{~h}$.

Phase identification was made by X-ray diffraction (XRD) at room temperature (DRON-6 diffractometer, $\mathrm{CuK}_{\alpha}$ radiation, angle range $2 \theta=20-120^{\circ}$, step $0.04^{\circ}, 10 \mathrm{~s} /$ step) and on heating up to $800{ }^{\circ} \mathrm{C}$ (Equinox 3000 instrument, Inel, France, equipped with the position sensitive detector and high-temperature camera HTK1200 Anton Paar, Austria). For the unit cell parameter calculations and full-profile Rietveld refinement, the CelRef v.4.0 and Fullprof 2008 were used $[16,17]$.

Thermogravimetric analysis (TGA) was carried out using a STA 409PC instrument (Netzsch) within the temperature range $25-1100{ }^{\circ} \mathrm{C}$ in air in static (isothermal dwells for $10 \mathrm{~h}$ ) and dynamic (heating/cooling rate $2 \mathrm{~K} / \mathrm{min}$ ) modes. The absolute values of the oxygen content were determined by reducing the samples in a flow of dried $10 \mathrm{vol} \% \mathrm{H}_{2}-90 \mathrm{vol} \%$ Ar gas mixture on slow heating from room temperature up to $1100{ }^{\circ} \mathrm{C}$ until achieving constant weight of the sample, assuming $\mathrm{Sm}_{2} \mathrm{O}_{3}, \mathrm{BaO}$ and metallic $\mathrm{Co}$ and $\mathrm{Fe}$ as the final products. The accuracy of the oxygen content determination was not less than \pm 0.01 .

Thermal expansion of ceramic samples was measured using a high-temperature dilatometer DIL 402C (Netzsch) in the temperature range $25-1100{ }^{\circ} \mathrm{C}$ in air with the heating/cooling rate $5 \mathrm{~K} / \mathrm{min}$. Dense $\mathrm{SmBaCo}_{2-x} \mathrm{Fe}_{x} \mathrm{O}_{5+\delta}(x=0,0.2,0.4,0.6,0.8)$ ceramics for the dilatometric measurements were compacted in the form of $2 \times 2 \times 15 \mathrm{~mm}^{3}$ bars and sintered at $1200-1300{ }^{\circ} \mathrm{C}$ in air for $15 \mathrm{~h}$, with subsequent slow cooling $\left(\sim 1.5^{\circ} \mathrm{C} / \mathrm{min}\right)$. The relative density of the polished ceramic samples was no less than $90 \%$ of their theoretical values calculated from the XRD data. The same samples were used for the electrical conductivity measurements (4-probe DC technique). In order to assess interaction of $\mathrm{SmBaCO}_{2-x} \mathrm{Fe}_{x} \mathrm{O}_{5+\delta}$ and solid oxide electrolytes in the temperature range $900-1100{ }^{\circ} \mathrm{C}$, the corresponding mixtures with 1:1 weight ratio were annealed at various temperatures during $24 \mathrm{~h}$ in air and studied by XRD.

\section{Results and discussion}

XRD analysis showed that single-phase $\mathrm{SmBaCo}_{2-x} \mathrm{Fe}_{x} \mathrm{O}_{5+\delta}$ perovskites are formed within the range $0 \leq x \leq 1.1$. As for undoped $\mathrm{SmBaCO}_{2} \mathrm{O}_{5+\delta}$, the crystal structure of $\mathrm{SmBaCo}_{2-x} \mathrm{Fe}_{x} \mathrm{O}_{5+\delta}(0 \leq x \leq 0.5)$ was identified as orthorhombic (space group Pmmm), with the unit cell $a_{p} \times 2 a_{p} \times 2 a_{p}$ where $a_{p}$ is the primitive perovskite unit cell parameter. As an example, Fig. 1a presents XRD pattern of $\mathrm{SmBaCo}_{1.8} \mathrm{Fe}_{0.2} \mathrm{O}_{5+\delta}$ refined by the Rietveld method; the structural parameters are summarized in Tables 1 and 2. On further increase of the iron content, the orthorhombic structure transforms into the $a_{p} \times a_{p} \times 2 a_{p}$ tetragonal polymorph (S.G. P4/mmm, Fig. $1 \mathrm{~b}$ ). At room temperature single tetragonal phases in the $\mathrm{SmBaCo}_{2-x} \mathrm{Fe}_{x} \mathrm{O}_{5}$ $+\delta$ system exist in the range $0.6 \leq x \leq 1.1$.

According to the XRD results all $\mathrm{SmBaCO}_{2-x} \mathrm{Fe}_{x} \mathrm{O}_{5+\delta}$ samples with $x \geq 1.2$ were multiphase. The samples with $x=1.2-1.5$ comprised the double perovskite of the limiting composition, $\mathrm{SmBaCO}_{0.9} \mathrm{Fe}_{1.1} \mathrm{O}_{5+\delta}$, and two disordered perovskite phases: $\mathrm{SmFe}_{1-z} \mathrm{Co}_{z} \mathrm{O}_{3-\delta}$ with orthorhombic structure and cubic samariumbarium ferrite. The materials with $x=1.6-2.0$ were two-phase; no traces of the double perovskite were detected.
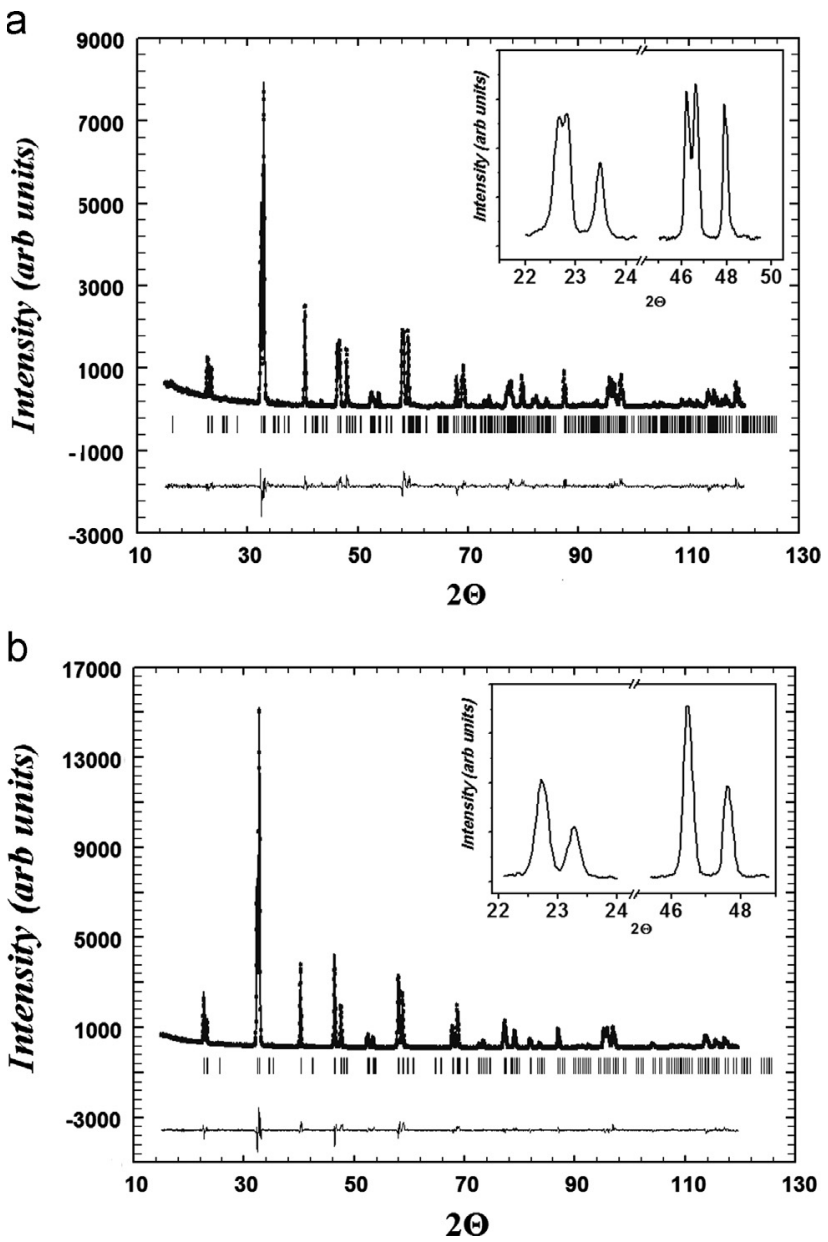

Fig. 1. Rietveld refinement profiles of $\mathrm{SmBaCo}_{1-x} \mathrm{Fe}_{0 . x} \mathrm{O}_{5+\delta}$ with $x=0.2$ (a) and 0.8 (b) circles are the experimental XRD data, upper continuous line is the calculated profile, lower continuous line is the difference plot, vertical lines are indicating the Bragg positions. Insets are showing the differences appeared between the orthorhombic (a) and tetragonal (b) cells.

The incorporation of iron into the cobalt sublattice results in a gradual increase of the unit cell parameters and volume (Fig. 2 and Table 2), since the ionic radius of iron is larger than that of cobalt (for 6-fold coordination $r_{\mathrm{Fe}^{3+}} / r_{\mathrm{Fe}^{4+}}=0.785 / 0.725 \AA$ and $r_{\mathrm{Co}^{3+}} / r_{\mathrm{Co}^{4+}}=$ $0.75 / 0.67 \AA$ ) [18]. Fig. 2 also illustrates the change of crystal structure from orthorhombic to tetragonal in the range of $x=0.5-0.6$.

Fig. 3 displays the variations of oxygen content in $\mathrm{SmBaCo}_{2}$ ${ }_{-x} \mathrm{Fe}_{x} \mathrm{O}_{5+\delta}(x=0-0.6)$ as a function of temperature in air. The excellent agreement between the data obtained in the continuous heating regime and in the regime with dwells at each temperature (points) confirms fast interfacial oxygen-exchange kinetics known in the literature. The oxygen content increases with increasing iron concentration in $\mathrm{SmBaCO}_{2-x} \mathrm{Fe}_{x} \mathrm{O}_{5+\delta}$ (Fig. 3). This can be understood considering the fact that iron is more electropositive compared to cobalt $\left(\chi_{\mathrm{Fe}}=1.64 ; \chi_{\mathrm{Co}}=1.7\right.$ according to the Allred and Rochow scale [19]). The iron cations act therefore as donors of electrons $\left(\mathrm{Fe}_{\mathrm{C}_{0}}^{\cdot}\right)$, preventing the formation of oxygen vacancies $\left(V_{0}^{\bullet \bullet}\right)$. The same tendency was earlier reported for other rare-earth and barium cobaltites [10-15].

Fig. 4 presents typical temperature dependencies of the linear thermal expansion of $\mathrm{SmBaCo}_{2-x} \mathrm{Fe}_{x} \mathrm{O}_{5+\delta}$, for $x=0$ and 0.2 . Note that no hysteresis between the dilatometric data collected on heating and cooling was observed, again confirming fast oxygenexchange kinetics. The materials with orthorhombic structure exhibit a moderately nonlinear behavior at $400-500{ }^{\circ} \mathrm{C}$, clearly visible in the differential curves (inset in Fig. 4) and indicative of a 
Table 1

Atomic positions in orthorhombic $\mathrm{SmBaCo}{ }_{1.8} \mathrm{Fe}_{0.2} \mathrm{O}_{5+\delta}$ and tetragonal $\mathrm{SmBaCo}_{1.2} \mathrm{Fe}_{0.8} \mathrm{O}_{5+\delta}$ refined by the Rietveld analysis.

\begin{tabular}{|c|c|c|c|c|c|c|c|c|c|}
\hline \multicolumn{5}{|c|}{$\mathrm{SmBaCo}_{1.8} \mathrm{Fe}_{0.2} \mathrm{O}_{5.71}$ (S.G. Pmmm) } & \multicolumn{5}{|c|}{$\mathrm{SmBaCo}_{1.2} \mathrm{Fe}_{0.8} \mathrm{O}_{5+\delta}$ (S.G. P4/mmm) } \\
\hline Atom & $x$ & $y$ & $z$ & $B_{i s o}, \AA^{2}$ & Atom & $x$ & $y$ & $z$ & $B_{\text {iso }}, \AA^{2}$ \\
\hline $\mathrm{Sm}$ & 0.5 & $0.239(2)$ & 0.5 & $0.25(4)$ & $\mathrm{Sm}$ & 0.5 & 0.5 & 0 & $0.28(4)$ \\
\hline $\mathrm{Ba}$ & 0.5 & $0.248(1)$ & 0 & $0.59(4)$ & $\mathrm{Ba}$ & 0.5 & 0.5 & 0.5 & $0.49(4)$ \\
\hline $\mathrm{Co}(\mathrm{Fe}) 1$ & 0 & 0.5 & $0.252(1)$ & $0.24(4)$ & $\mathrm{Co}(\mathrm{Fe})$ & 0 & 0 & $0.247(2)$ & $0.16(4)$ \\
\hline $\mathrm{Co}(\mathrm{Fe}) 2$ & 0 & 0 & $0.251(2)$ & $0.38(4)$ & 01 & 0 & 0 & 0 & $0.69(4)$ \\
\hline 01 & 0 & 0 & 0 & $0.85(4)$ & $\mathrm{O} 2$ & 0 & 0 & 0.5 & $0.69(4)$ \\
\hline $\mathrm{O} 2$ & 0 & 0.5 & 0 & $0.62(4)$ & 03 & 0 & 0.5 & $0.214(2)$ & $1.03(4)$ \\
\hline $\mathrm{O} 3$ & 0 & 0.5 & 0.5 & $0.50(4)$ & & & & & \\
\hline $\mathrm{O} 4$ & 0 & 0 & 0.5 & $0.73(4)$ & & & & & \\
\hline $\mathrm{O} 5$ & 0.5 & 0 & $0.277(3)$ & $0.69(4)$ & & & & & \\
\hline O6 & 0.5 & 0.5 & $0.305(3)$ & $0.54(4)$ & & & & & \\
\hline $\mathrm{O} 7$ & 0 & $0.253(2)$ & $0.289(1)$ & $0.67(4)$ & & & & & \\
\hline \multicolumn{5}{|c|}{$\begin{array}{l}a=3.887(1) \AA ; \quad b=7.831(1) \AA ; ; c=7.568(1) \AA ; V=230.36(2)(\AA)^{3} ; R_{B r}=15.0 \% ; R_{f}=13.6 \% \\
\quad R_{p}=12.3 \%\end{array}$} & \multicolumn{5}{|c|}{$\begin{array}{l}a=b=3.906(1) \AA ̊ ; c=7.629(1) \AA ; V=116.39(2)(\AA)^{3} ; R_{B r}=10.1 \% ; R_{f}=8.10 \% ; \\
R_{p}=9.16 \%\end{array}$} \\
\hline
\end{tabular}

Table 2

Unit cell parameters of $\mathrm{SmBaCo}_{2-x} \mathrm{Fe}_{x} \mathrm{O}_{5+\delta}$, extracted from the Rietveld refinement results, and relevant agreement factors ${ }^{\mathrm{a}}$.

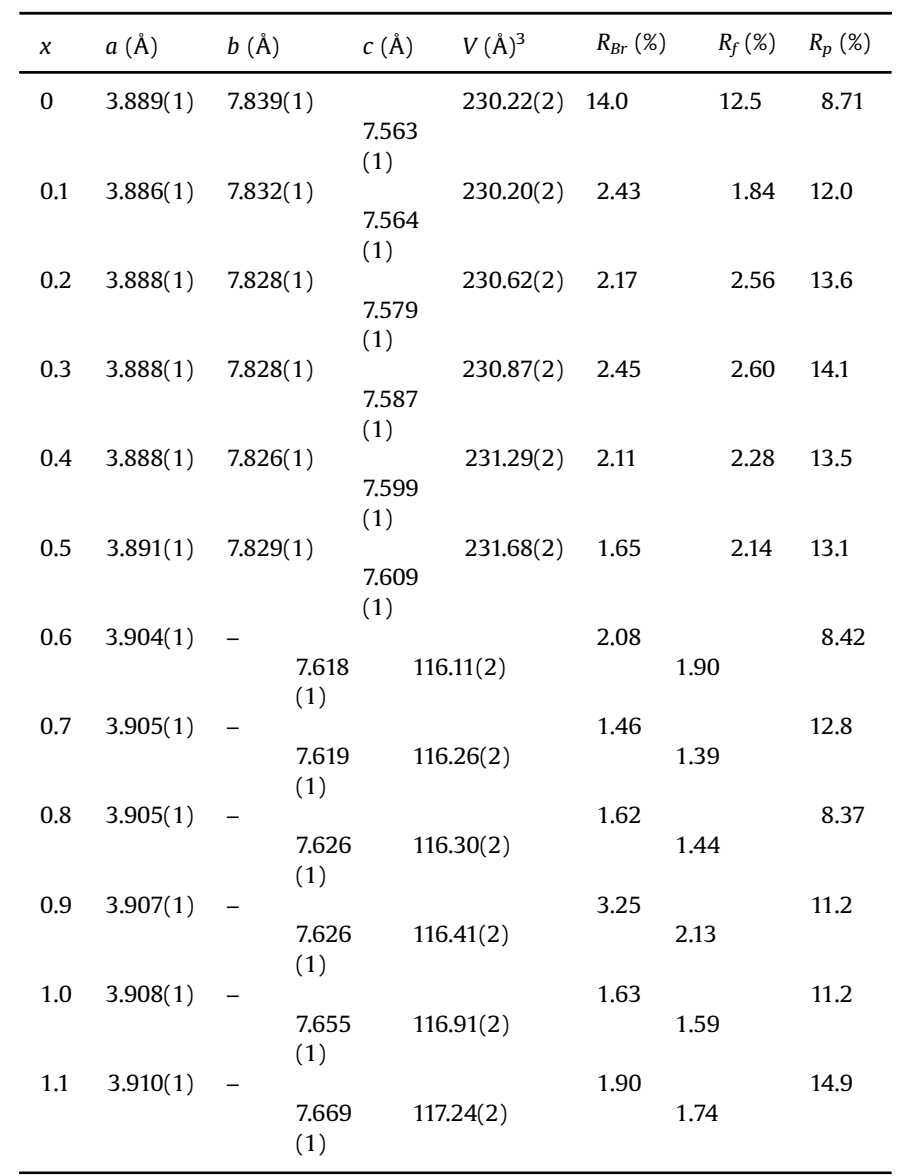

${ }^{\mathrm{a}} R_{\mathrm{Br}}$ is the Bragg factor, $R_{f}$ is the structural factor, and $R_{p}$ is the profile factor.

phase transition. In accordance with high-temperature XRD data discussed below, these features originate from the orthorhombic $\rightarrow$ tetragonal transformation, shifted due to the variations of oxygen content. For the materials with tetragonal structure $(x \geq 0.6)$, the expansion is essentially linear in the entire temperature range studied in this work. The average thermal expansion coefficients (TECs) calculated from the dilatometric data remain practically independent of the iron content, Table 3.

In order to confirm the nature of the abovementioned phase transition in situ high-temperature XRD studies were performed.

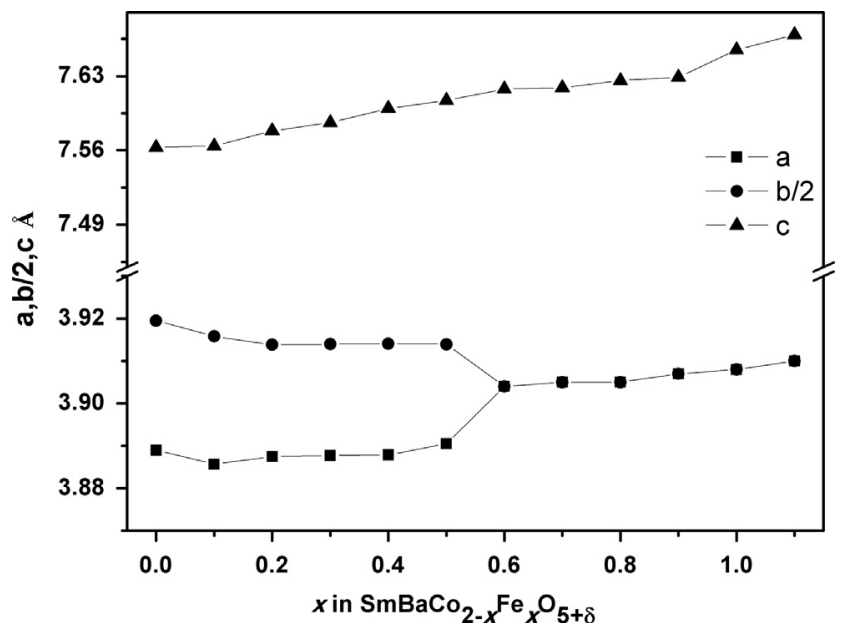

Fig. 2. The unit cell parameters of $\mathrm{SmBaCo}_{2-x} \mathrm{Fe}_{x} \mathrm{O}_{5+\delta}$ versus iron concentration.

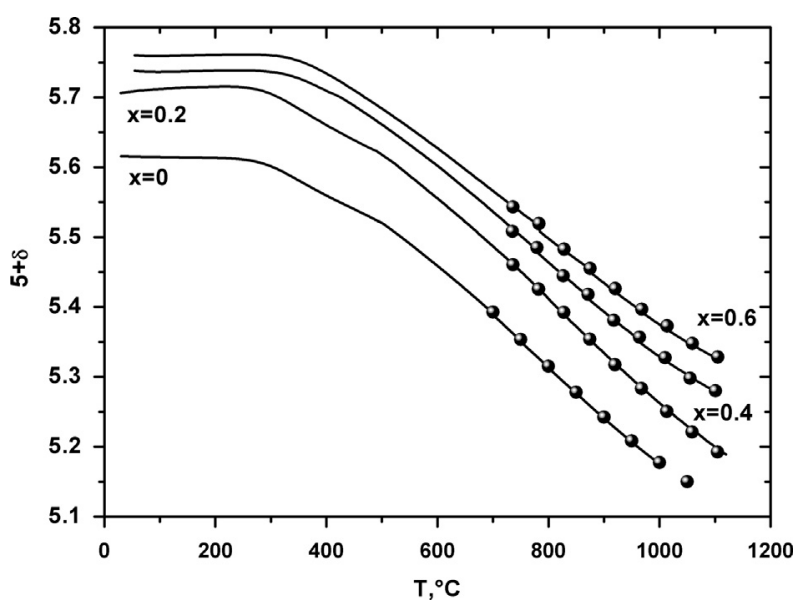

Fig. 3. Oxygen content in $\mathrm{SmBaCo}_{2-x} \mathrm{Fe}_{x} \mathrm{O}_{5+\delta}$ at atmospheric oxygen pressure. Solid lines representing TGA data obtained in dynamic regime, point were obtained in static regime (see text).

As an example, Figs. 5 and 6 show selected XRD patterns of undoped $\mathrm{SmBaCO}_{2} \mathrm{O}_{5+\delta}$ and temperature dependence of the unit cell parameters, respectively. The transformation from orthorhombic into tetragonal unit cell takes place between 450 and $500{ }^{\circ} \mathrm{C}$.

The temperature dependencies of the total conductivity of $\mathrm{SmBaCO}_{2-x} \mathrm{Fe}_{x} \mathrm{O}_{5+\delta}(x=0-0.6)$ all possess maxima at approximately $300-350{ }^{\circ} \mathrm{C}$ (Fig. 7). For the family of rare earth barium cobaltates 


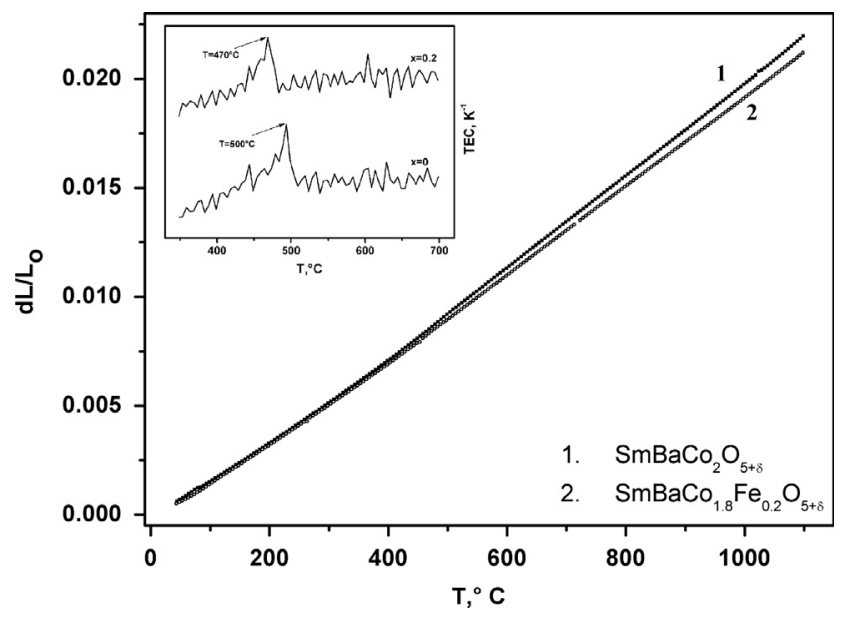

Fig. 4. Thermal expansion of $\mathrm{SmBaCo}_{2-x} \mathrm{Fe}_{x} \mathrm{O}_{5+\delta}$ ceramics in air. Inset shows the first derivative of $d L / L_{0}$ versus temperature.

Table 3

Average thermal expansion coefficients of $\mathrm{SmBaCo}_{2-x} \mathrm{Fe}_{x} \mathrm{O}_{5+\delta}$ in air.

\begin{tabular}{lcl}
\hline$x$ & $T,{ }^{\circ} \mathrm{C}$ & $\mathrm{TEC} \times 10^{6}, \mathrm{~K}^{-1}$ \\
\hline \multirow{2}{*}{0} & $25-500$ & 18.7 \\
& $500-1100$ & 21.1 \\
0.2 & $25-470$ & 18.4 \\
& $460-1100$ & 20.4 \\
0.4 & $25-400$ & 19.0 \\
0.6 & $400-1100$ & 20.8 \\
0.8 & $25-1100$ & 21.2 \\
& $25-1100$ & 21.0 \\
\hline
\end{tabular}

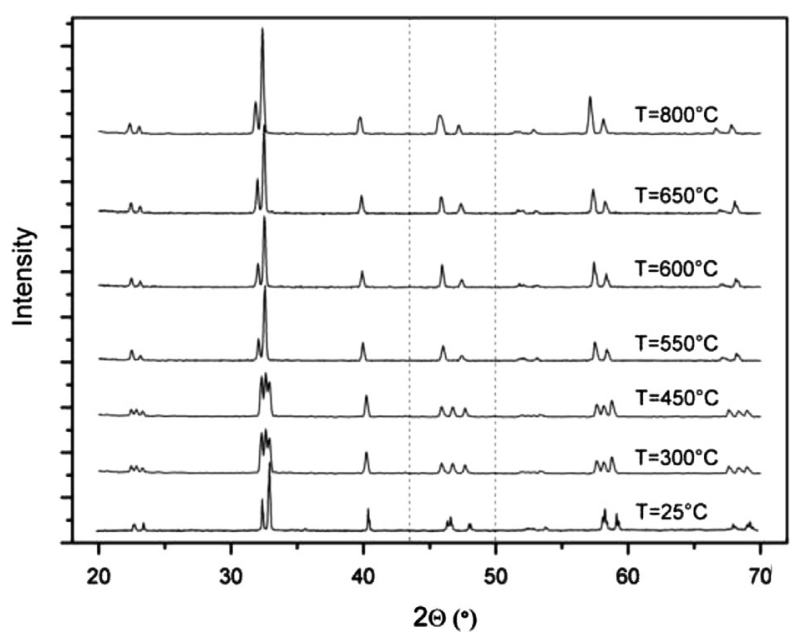

Fig. 5. High-temperature XRD patterns of $\mathrm{SmBaCo}_{2} \mathrm{O}_{5+\delta}$.

with the double perovskite structure it was shown earlier that the transport properties are governed by the p-type electronic charge carriers [20,21].

At relatively low temperatures $\left(25-300^{\circ} \mathrm{C}\right)$ when oxygen exchange between the solid and gaseous phase is negligible (Fig. 3 ), the increase of electrical conductivity can be explained by increasing the concentration of the electronic charge carriers due to the intrinsic charge disproportionation process $\left(2 \mathrm{Co}_{\mathrm{Co}_{0}}^{\times} \Leftrightarrow \mathrm{Co}_{\mathrm{Co}_{0}}^{\prime}+\mathrm{Co}_{\mathrm{Co}_{0}}^{\bullet}\right)$, as for the mobility. Further increase of temperature leads to the noticeable decrease of oxygen content that resulted in substantially higher oxygen-vacancy concentration, $\left[\mathrm{V}_{\mathrm{O}}^{\bullet}\right]$. The latter influences the disproportionation reaction equilibrium, shifting it towards trivalent cobalt states and, hence, decreasing the concentration of mobile

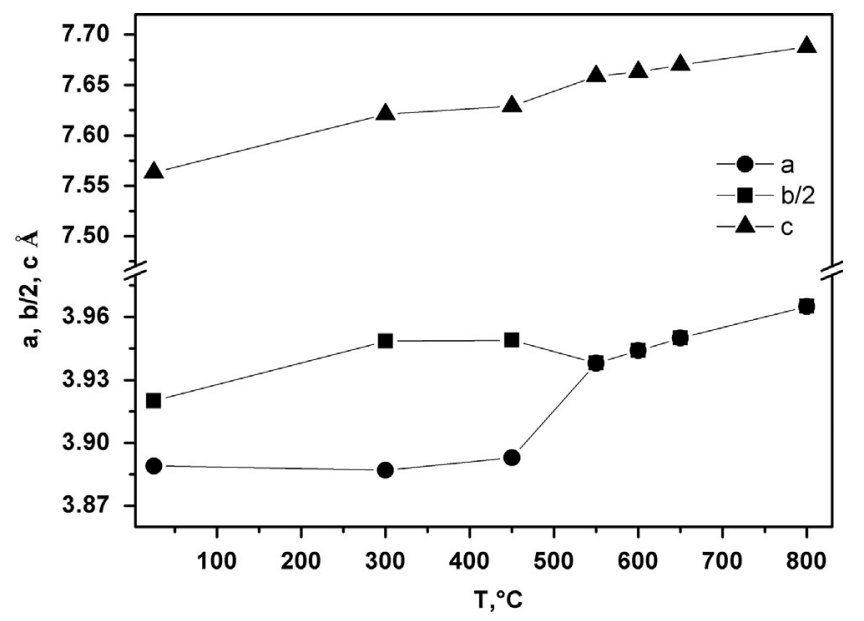

Fig. 6. Temperature dependencies of the unit cell parameters and volume of $\mathrm{SmBaCO}_{2} \mathrm{O}_{5+\delta}$.

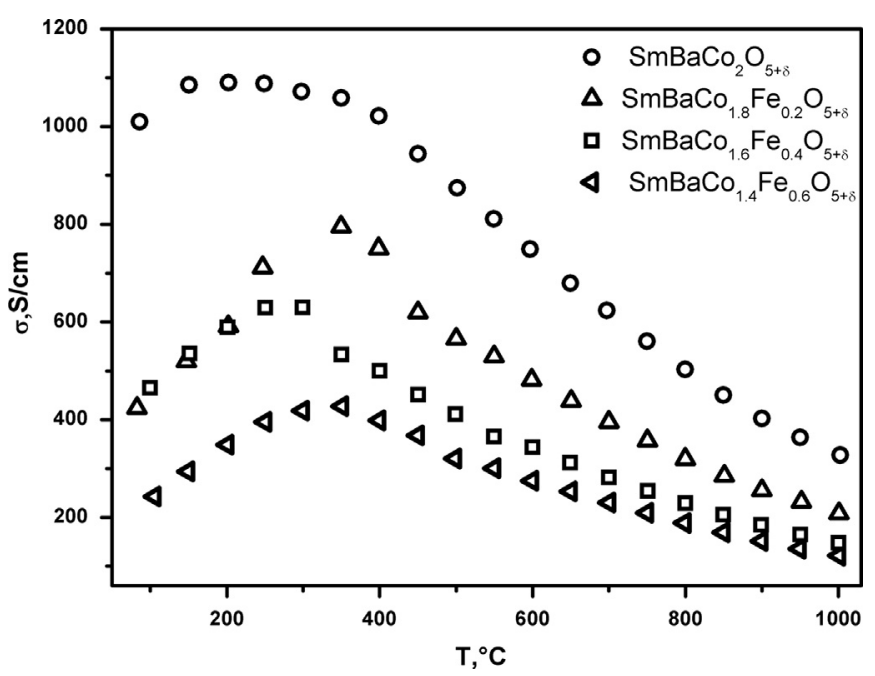

Fig. 7. Temperature dependencies of the total conductivity of dense $\mathrm{SmBaCO}_{2-x}$ $\mathrm{Fe}_{x} \mathrm{O}_{5+\delta}$ ceramics.

charge carriers $\left[\mathrm{Co}_{\mathrm{Co}}^{\bullet}\right]$. Similar changes in the concentrations of defect species in $\mathrm{GdBaCo}_{2} \mathrm{O}_{5+\delta}$ were reported by Tsvetkov et al. [22]. The decrease of electrical conductivity for the partially Fe-substituted $\mathrm{SmBaCO}_{2-x} \mathrm{Fe}_{x} \mathrm{O}_{5+\delta}$ is in excellent agreement with the suggested model since iron is more electropositive in comparison to cobalt ion and acts as the hole trap $\mathrm{Fe}_{\mathrm{C} \text {. }}^{\circ}$.

Finally, XRD analysis of the mixtures comprising $\mathrm{SmBaCO}_{2-\gamma} \mathrm{Fe}_{x} \mathrm{O}_{5+\delta}$ and $\mathrm{Ce}_{0.8} \mathrm{Sm}_{0.2} \mathrm{O}_{1.9}$ or $\mathrm{Zr}_{0.85} \mathrm{Y}_{0.15} \mathrm{O}_{1.93}$ showed that no chemical reactions occur between the title materials and doped ceria at $900-1100{ }^{\circ} \mathrm{C}$. Selected examples of the XRD patterns are presented in Fig. 8. On the contrary, an extensive interaction yielding $\mathrm{BaZrO}_{3}$ was observed in the phase mixtures containing yttria-stabilized zirconia, irrespective of the iron concentration in $\mathrm{SmBaCO}_{2-\gamma} \mathrm{Fe}_{x} \mathrm{O}_{5+\delta}$. This reaction, and the very large difference in the TECs of $\mathrm{SmBaCO}_{2-x} \mathrm{Fe}_{x} \mathrm{O}_{5+\delta}$ (Table 3) and zirconia electrolytes [23], makes it impossible to use cobaltate electrodes in contact with $\mathrm{Zr}_{0.85} \mathrm{Y}_{0.15} \mathrm{O}_{1.93}$ or similar solid electrolytes. In the case of $\mathrm{Ce}_{0.8} \mathrm{Sm}_{0.2} \mathrm{O}_{1.9}$, the thermal expansion mismatch is lower although still critical.

\section{Conclusion}

The perovskite-like solid solution formation range in the $\mathrm{SmBaCo}_{2-x} \mathrm{Fe}_{x} \mathrm{O}_{5+\delta}$ system corresponds to $0 \leq x \leq 1.1$ at $1100{ }^{\circ} \mathrm{C}$ in 

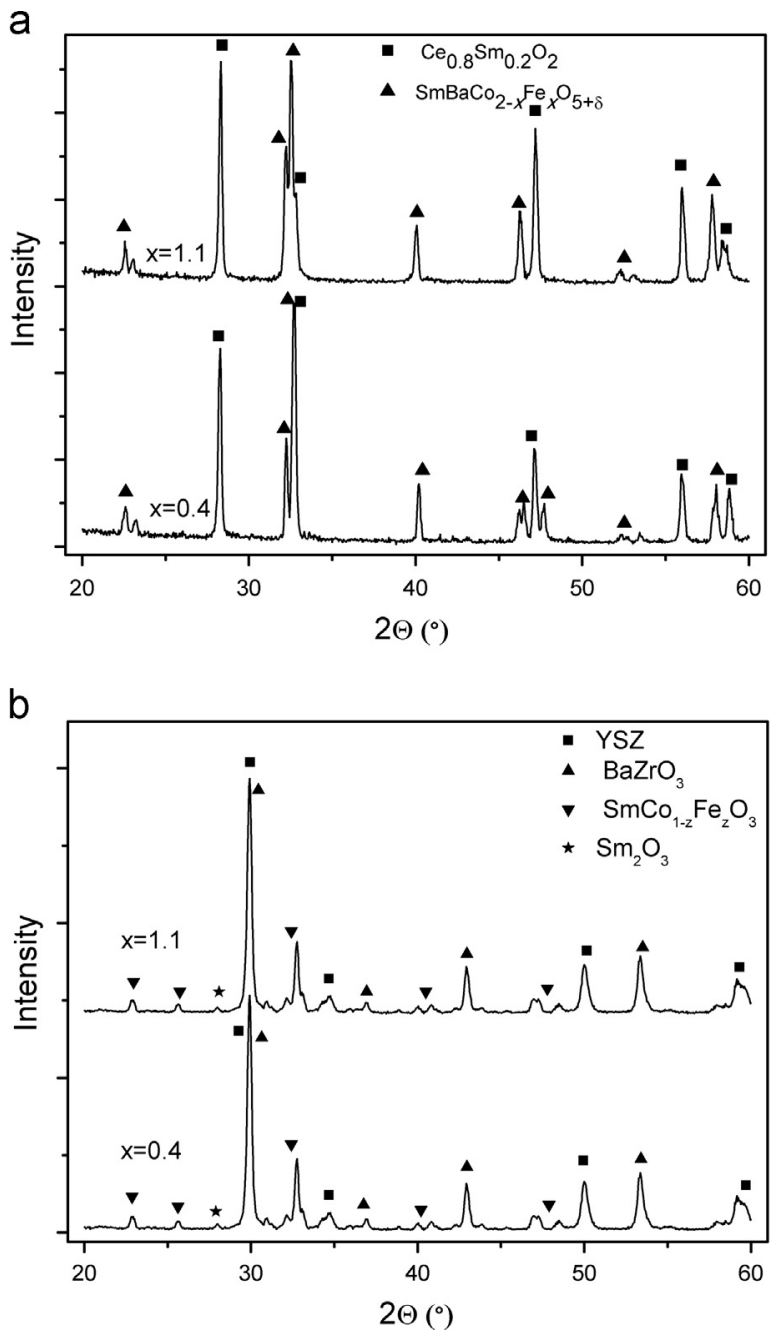

Fig. 8. XRD patterns of the mixtures (50:50 wt\%) containing $\mathrm{SmBaCO}_{2-x} \mathrm{Fe}_{x} \mathrm{O}_{5+\delta}$ $\left(x=0.4\right.$ and 1.1) and $\mathrm{Ce}_{0.8} \mathrm{Sm}_{0.2} \mathrm{O}_{1.9}$ (a) or $\mathrm{Zr}_{0.85} \mathrm{Y}_{0.15} \mathrm{O}_{1.93}$ (b) after annealing in air at $1100{ }^{\circ} \mathrm{C}(\mathrm{a})$ and $900{ }^{\circ} \mathrm{C}(\mathrm{b})$ during $24 \mathrm{~h}$.

air. The double perovskites with $0 \leq x \leq 0.5$ possess orthorhombic structure (S.G. Pmmm) with $a_{p} \times 2 a_{p} \times 2 a_{p}$ unit cell. At $0.6 \leq x \leq 1.1$ the tetragonal $a_{p} \times a_{p} \times 2 a_{p}$ structure (S.G. P4/mmm) is formed. The unit cell volume and oxygen content in the solid solutions increase with $x$. Temperature dependencies of the electrical conductivity exhibit maxima at the temperatures when oxygen exchange with the gaseous phase becomes significant and oxygen losses from the perovskite lattice start. The partial substitution of iron for cobalt leads to a lower conductivity. All these facts can be explained based on the existing defect model for the double perovskite cobaltates. The average thermal expansion coefficients and reactivity with zirconia-based solid electrolyte at $900-1100{ }^{\circ} \mathrm{C}$ are essentially unaffected by iron doping. No chemical reaction between $\mathrm{SmBaCO}_{2-x} \mathrm{Fe}_{x} \mathrm{O}_{5+\delta}$ and $\mathrm{Ce}_{0.8} \mathrm{Sm}_{0.2} \mathrm{O}_{1.9}$ occurs in this temperature range.

\section{Acknowledgments}

This work was financially supported in parts by the Russian Foundation for Basic Research (Project No. 13-03-00958_a), the Ministry for Education and Science of the Russian Federation within the Federal Target Programs "Investigations and researches on the priority directions of development for the scientific and technological complex of Russia in 2007-2013", and "The scientific and scientific-education personnel of Innovative Russia for 20092013" and the FCT, Portugal (Projects PEst-C/CTM/LA0011/2011, PTDC/CTM-CER/114561/2009).

\section{Appendix A. Supporting information}

Supplementary data associated with this article can be found in the online version at http://dx.doi.org/10.1016/j.jssc.2013.06.001.

\section{References}

[1] J.-H. Kim, A. Manthiram, J. Electrochem. Soc. 155 (2008) B385-B390.

[2] Q. Zhou, T. He, Y. Ji, J. Power Sources 185 (2008) 754-758.

[3] A. Tarascón, S.J. Skinner, R.J. Chater, F. Hernández-Ramírez, J.A. Kilner, J. Mater. Chem. 17 (2007) 3175-3181.

[4] J.H. Kim, Y. Kim, P.A. Connor, J.T.S. Irvine, J. Bae, W. Zhou, J. Power Sources 194 (2009) 704-711.

[5] A. Maignan, C. Martin, D. Pelloquin, N. Nguyen, B. Raveau, J. Solid State Chem. 142 (1999) 247-260.

[6] P.S. Anderson, C.A. Kirk, J. Knudsen, I.M. Reaney, A.R. West, Solid State Sci. 7 (2005) 1149-1156.

[7] Md.Motin Seikh, Ch. Simon, V. Caignaert, V. Pralong, M.B. Lepetit, S. Boudin, B. Raveau, Chem. Mater. 20 (2008) 231-238.

[8] E. Chavez, M. Mueller, L. Mogni, A. Caneiro, J. Phys.: Conf. Ser. 167 (2009) 1-6 012043.

[9] J.-H. Kim, L. Mogni, F. Prado, A. Caneiro, J.A. Alonso, A. Manthiram, J. Electrochem. Soc. 156 (2009) B1376-B1382.

[10] D.S. Tsvetkov, I.L. Ivanov, I.V. Urusov, A.Yu. Zuev, Thermochim. Acta 519 (2011) $12-15$.

[11] V.A. Cherepanov, T.V. Aksenova, L.Ya. Gavrilova, K.N. Mikhaleva, Solid State Ionics 188 (2011) 53-57.

[12] D.S. Tsvetkov, V.V. Sereda, N.S. Saricheva, A.Yu. Zuev, J. Fuel Cells: Sci. Technol. 8 (2011) 041006-041010.

[13] J. Xue, Y. Shen, T. He, J. Power Sources 196 (2011) 3729-3735.

[14] Y.N. Kim, J.-H. Kim, A. Manthiram, J. Power Sources 195 (2010) 6411-6419.

[15] V.A. Cherepanov, L.Ya. Gavrilova, T.V. Aksenova, A.S. Urusova, N.E. Volkova, Mater. Res. Soc. Symp. Proc. (2012), http://dx.doi.org/10.1557/opl.2012.325.

[16] V.K. Pecharsky, P.Y. Zavalij, Fundamentals of Powder Diffraction and Structural Characterization of Materials, second ed., Springer, New York, 2005.

[17] R.E. Dinnebier, S.J.L. Billinge, Powder Diffraction. Theory and Practice, RSC Publ., Cambridge, 2008.

[18] R.D. Shannon, Acta Cryst 32 (1976) 751-767.

[19] J.E. Huheey, Inorganic Chemistry, Harper \& Row, New York, 1983.

[20] T.V. Aksenova, L.Yu. Gavrilova, A.A. Yaremchenko, V.A. Cherepanov, V.V. Kharton, Mater. Res. Bull. 45 (2010) 1288-1292.

[21] D.S. Tsvetkov, V.V. Sereda, A.Yu. Zuev, Solid State Ionics 192 (2011) 215-219.

[22] D.S. Tsvetkov, V.V. Sereda, A.Yu. Zuev, Solid State Ionics 180 (2010) 1620-1625.

[23] E.V. Tsipis, V.V. Kharton, J. Solid State Electrochem. 12 (2008) 1039-1060. 